\title{
BMJ Open Type 1 diabetes incidence trends in children and adolescents aged 0-14 years in Europe: a systematic review and meta-analysis protocol
}

\author{
Ana Díez-Fernández (D) , ${ }^{1}$ Marta Carolina Ruiz-Grao, ${ }^{2}$ Arthur Eumann Mesas, ${ }^{1}$ \\ Vicente Martinez-Vizcaino, ${ }^{3}$ Miriam Garrido-Miguel ${ }^{1}$
}

To cite: Díez-Fernández A, RuizGrao MC, Mesas AE, et al. Type 1 diabetes incidence trends in children and adolescents aged $0-14$ years in Europe: a systematic review and metaanalysis protocol. BMJ Open 2021;11:e054962. doi:10.1136/ bmjopen-2021-054962

- Prepublication history for this paper is available online. To view these files, please visit the journal online (http://dx.doi. org/10.1136/bmjopen-2021054962).

Received 04 July 2021 Accepted 28 September 2021

D) Check for updates

(c) Author(s) (or their employer(s)) 2021. Re-use permitted under CC BY-NC. No commercial re-use. See rights and permissions. Published by BMJ.

${ }^{1}$ Social and Health Care Research Center, Universidad de Castilla-La Mancha, Cuenca, Spain

${ }^{2}$ Faculty of Nursing, Universidad de Castilla-La Mancha, Albacete, Spain

${ }^{3}$ Centro de Estudios

Sociosanitarios, Universidad de Castilla-La Mancha, Cuenca, Spain

Correspondence to Dr Marta Carolina Ruiz-Grao; Marta.Ruiz@uclm.es

\section{ABSTRACT}

Introduction Monitoring type 1 diabetes (T1D) trends across most European countries using objectively measured data and how this incidence has evolved over the past three decades should be considered a public health priority. This study protocol provides a standardised and transparent methodology to assess TD1 trends among 0-14-year-old children and adolescents across Europe from 1994 to 2021.

Methods and analysis This protocol is guided by the Preferred Reporting Items for Systematic Review and Meta-Analysis Protocols and the Cochrane Collaboration Handbook. The literature search will be conducted using MEDLINE, Embase, CINAHL and Web of Science databases from 1994 to 2021. Observational cohort studies providing incidence rates for European children and adolescents diagnosed with T1D aged $\leq 14.9$ years and studies written in English, Spanish or Portuguese will be included. The risk of bias of the included studies will be assessed using the Quality Assessment Tool for Observational Cohort and Cross-Sectional Studies from the National Heart, Lung, and Blood Institute. Subgroup analyses will be performed based on gender, age, study year, country or European region. Metaregression analysis will be conducted using economic and geographic variables, such as gross national income of the country or geographic latitude.

Ethics and dissemination The systematic review based on this protocol will provide a comprehensive description of T1D incidence trends in children and adolescents across Europe from 1994 to 2021. The results will be disseminated in a peer-reviewed journal and in mass media. This study will exclusively use data from published research, so institutional ethical approval is not required. PROSPERO registration number CRD42021239480.

\section{INTRODUCTION}

The global incidence of newly diagnosed cases of type 1 diabetes (T1D) in children and adolescents increased annually by approximately 3\% until 1999 despite observed geographical differences. ${ }^{1}$ In 2019, the International Diabetes Federation indicated that every year, 98200 children and adolescents aged 0-14 years are diagnosed with T1D
Strength and limitations of this study

- This systematic review and meta-analysis protocol presents a comprehensive and standardised methodology to synthesise relevant studies for monitoring trends in type 1 diabetes among children and adolescents across most European countries and regions.

- Subgroup analyses based on gender, age group, time period, European country and region will improve the quality of our estimates.

- Data extraction, study selection and risk-of-bias assessment will be performed independently by two researchers.

- Differences in sample characteristics, quality of the included data and geographical location may increase heterogeneity between studies, which might reduce the quality of evidence on time trends in type 1 diabetes.

worldwide. ${ }^{2}$ Although important conclusions can be derived from these analyses, incidence rates are collected from population-based prospective registries, and these studies are commonly conducted in wealthy countries only. ${ }^{3}$

In this regard, with the creation of the Europe and Diabetes Study (EURODIAB) in 1989, the incidence of T1D in Europe in children and adolescents aged 0-14.9 years has been updated every year with data from 26 European centres representing 22 countries. The 2019 report, which included data from 1989 to 2013 , indicated an overall pooled rate of an annual increase of $3.4 \%(2.8 \%-3.9 \%){ }^{4}$

However, specific data from different studies are not included in the EURODIAB studies, such as incidence studies conducted in other regions ${ }^{5-8}$ or other centres in countries that are included in the EURODIAB Family Study. Thus, monitoring T1D trends across most European countries using data objectively measured and obtained in 
different regions can provide a more complete picture of the epidemiological situation in Europe.

To date, no study has examined data on the incidence of T1D in most European countries and regions in children and adolescents during the last three decades. This information would provide a more comprehensive picture of the epidemiological situation regarding T1D and also extend knowledge towards possible economic and geographical disparities across the continent.

Therefore, the present study protocol reports a standardised and transparent methodology for conducting a systematic review and meta-analysis aimed at assessing the incidence and trends in T1D among European children aged 0-14 years in Europe from 1994 to 2021 using systematic methodology.

\section{OBJECTIVES}

The purpose of this study protocol is to report a standardised and transparent methodology for conducting a systematic review and meta-analysis aimed at (1) assessing the trends of T1D among 0-14.9-year-old children and adolescents across Europe from 1994 to 2021 and (2) analysing whether T1D incidence trends have varied based on gender, age, country, European region, gross national income of the country or geographical latitude.

\section{METHODS/DESIGN}

This systematic review and meta-analysis protocol is based on the Preferred Reporting Items for Systematic Review and Meta-Analysis Protocols ${ }^{910}$ and the Cochrane Collaboration Handbook. ${ }^{11}$.

\section{Inclusion/exclusion criteria for study selection}

We will include studies providing incidence rates of European children and adolescents diagnosed with T1D aged $\leq 14.9$ years who meet the following inclusion criteria: (1) observational studies (cohort studies); (2) studies reporting data by year or periods of time; and (3) studies including incidence rates and/or mean annual incidence.

However, studies will be excluded from the analyses when (1) they do not provide details of the sampling method or the sample composition and (2) they refer to a particular population group, such as aboriginal groups, immigrant groups, economic status or concomitant diseases.

\section{Search strategy}

The literature search will be conducted using MEDLINE (via PubMed), Embase (via Scopus), CINAHL and Web of Science databases from 1994 to June 2021 with no language restrictions.

Study records will be managed using the Mendeley reference manager. The following search terms will be combined using Boolean operators from the search concepts, as described in table 1.
Table 1 Search strategy for the MEDLINE database

\begin{tabular}{|c|c|}
\hline \multicolumn{2}{|c|}{ Search set MEDLINE } \\
\hline$\# 1$ & Children [All Fields) \\
\hline \#2 & Childhood [All Fields) \\
\hline \#3 & Schooler [All Fields) \\
\hline \#4 & Toddlers [All Fields) \\
\hline \#5 & Preadolescents [All Fields) \\
\hline \#6 & Adolescent [All Fields) \\
\hline \#7 & Infan* [All Fields) \\
\hline \#8 & Pediatr* OR Paedriatr ${ }^{\star}$ (All Fields) \\
\hline$\# 9$ & Child* [All Fields) \\
\hline \#10 & Teenag* [All Fields) \\
\hline \#11 & Youth [All Fields) \\
\hline \#12 & Young [All Fields) \\
\hline \#13 & School [All Fields) \\
\hline \#14 & School aged [All Fields) \\
\hline \#15 & School-aged [All Fields) \\
\hline \#16 & $\begin{array}{l}\text { 1 OR } 2 \text { OR } 3 \text { OR } 4 \text { OR } 5 \text { OR } 6 \text { OR } 7 \text { OR } 8 \text { OR } 9 \text { OR } 10 \text { OR } \\
11 \text { OR } 12 \text { OR } 13 \text { OR } 14 \text { OR } 15\end{array}$ \\
\hline \#17 & Diabetes Mellitus [All Fields) \\
\hline \#18 & Diabetes Mellitus, Type 1 [MeSH Terms) \\
\hline \#19 & Diabetes Mellitus, Insulin-Resistant [MeSH Terms) \\
\hline \#20 & Diabetes Mellitus, Insulin-Dependent [All Fields) \\
\hline \#21 & T1D [All Fields) \\
\hline \#22 & 17 OR 18 OR 19 OR 20 OR 21 \\
\hline \#23 & Incidence [All Fields) \\
\hline \#24 & Trend [All Fields) \\
\hline \#25 & Epidemiolog* [All Fields) \\
\hline \#26 & 23 OR 24 OR 25 \\
\hline \#27 & observat* [All Fields) \\
\hline \#28 & cross-sectional [All Fields) \\
\hline \#29 & longitudinal [All Fields) \\
\hline \#30 & survey [All Fields) \\
\hline \#31 & 27 OR 28 OR 29 OR 30 NOT review \\
\hline \#32 & Russia [All Fields) \\
\hline \#33 & Germany [All Fields) \\
\hline \#34 & Turkey [All Fields) \\
\hline \#35 & France [All Fields) \\
\hline \#36 & United Kingdom [All Fields) \\
\hline \#37 & UK [All Fields) \\
\hline \#38 & Italy [All Fields) \\
\hline \#39 & Spain [All Fields) \\
\hline \#40 & Ukraine [All Fields) \\
\hline \#41 & Poland [All Fields) \\
\hline \#42 & Romania [All Fields) \\
\hline \#43 & Kazakhstan [All Fields) \\
\hline \#44 & Netherlands [All Fields) \\
\hline \#45 & Belgium [All Fields) \\
\hline \#46 & Greece [All Fields) \\
\hline
\end{tabular}

Continued 


\section{Table 1 Continued}

\section{Search set MEDLINE}

\begin{tabular}{|c|c|}
\hline \#47 & Czech Republic [All Fields) \\
\hline \#48 & Portugal [All Fields) \\
\hline \#49 & Sweden [All Fields) \\
\hline \#50 & Hungary [All Fields] \\
\hline \#51 & Azerbaijan [All Fields] \\
\hline \#52 & Belarus [All Fields] \\
\hline \#53 & Austria [All Fields] \\
\hline \#54 & Switzerland [All Fields) \\
\hline \#55 & Bulgaria [All Fields] \\
\hline \#56 & Serbia [All Fields) \\
\hline \#57 & Denmark [All Fields) \\
\hline \#58 & Finland [All Fields) \\
\hline \#59 & Slovakia [All Fields) \\
\hline \#60 & Norway [All Fields) \\
\hline \#61 & Ireland [All Fields) \\
\hline \#62 & Croatia [All Fields) \\
\hline \#63 & Bosnia and Herzegovina [All Fields) \\
\hline \#64 & Georgia [All Fields) \\
\hline \#65 & Moldova [All Fields) \\
\hline \#66 & Armenia [All Fields) \\
\hline \#67 & Lithuania [All Fields) \\
\hline \#68 & Albania [All Fields) \\
\hline \#69 & Macedonia [All Fields) \\
\hline \#70 & Slovenia [All Fields) \\
\hline \#71 & Latvia [All Fields) \\
\hline \#72 & Kosovo [All Fields) \\
\hline \#73 & Estonia [All Fields) \\
\hline \#74 & Cyprus [All Fields) \\
\hline \#75 & Montenegro [All Fields) \\
\hline \#76 & Luxembourg [All Fields) \\
\hline \#77 & North Macedonia [All Fields) \\
\hline$\# 78$ & Malta [All Fields) \\
\hline \#79 & Iceland [All Fields) \\
\hline \#80 & Andorra [All Fields) \\
\hline \#81 & Liechtenstein [All Fields) \\
\hline \#82 & Monaco [All Fields) \\
\hline \#83 & San Marino [All Fields) \\
\hline \#84 & Vatican city [All Fields) \\
\hline \#85 & $\begin{array}{l}32 \text { OR } 33 \text { OR } 34 \text { OR } 35 \text { OR } 36 \text { OR } 37 \text { OR } 38 \text { OR } 39 \text { OR } \\
40 \text { OR } 41 \text { OR } 42 \text { OR } 43 \text { OR } 44 \text { OR } 45 \text { OR } 46 \text { OR } 47 \text { OR } \\
48 \text { OR } 49 \text { OR } 50 \text { OR } 51 \text { OR } 52 \text { OR } 53 \text { OR } 54 \text { OR } 55 \text { OR } \\
56 \text { OR } 57 \text { OR } 58 \text { OR } 59 \text { OR } 60 \text { OR } 61 \text { OR } 62 \text { OR } 63 \text { OR } \\
64 \text { OR } 65 \text { OR66 OR } 67 \text { OR } 68 \text { OR } 69 \text { OR } 70 \text { OR } 71 \text { OR } 72 \\
\text { OR } 73 \text { OR } 74 \text { OR } 75 \text { OR } 76 \text { OR } 77 \text { OR } 78 \text { OR } 79 \text { OR } 80 \\
\text { OR } 81 \text { OR } 82 \text { OR } 83 \text { OR } 84\end{array}$ \\
\hline \#86 & 16 AND 22 AND 26 AND 31 AND 85 \\
\hline
\end{tabular}

\section{Selection and analysis of trials}

To identify eligible studies, two of the reviewers will independently screen titles and abstracts. Then, the full manuscripts of the identified studies will be examined. Finally, two reviewers will remove duplicate studies and will check the included and excluded studies and verify the reasons why they were included/excluded. In the case of discrepancies, a consensus will be reached after the consultation of a third independent investigator. The selection process of eligible articles is shown in figure 1.

In parallel and independently, two authors will extract the following data from the included studies: first author's name, publication year, country, European region, level of representativeness (national/regional data), period of study, design, characteristics of the included population (sample size, age of participants and sex) and outcomes (mean annual incidence rates of type 1 diabetes by age group) (table 2).

The Grading of Recommendations, Assessment, Development and Evaluation tool will be used to assess the quality of the evidence and make recommendations. ${ }^{12}$ Each outcome will scored as high, moderate, low or very low evidence, depending on the study design, risk of bias, inconsistency, indirect evidence, imprecision and publication bias.

\section{Quality assessment: risk of bias}

The included studies will be assessed for methodological quality based on the full-published paper independently by two researchers using the tool according to the study type. The following tools will be used:

- Quality Assessment Tool for Observational Cohort and Cross-Sectional Studies from the National Heart, Lung, and Blood Institute (NIH). This tool includes 14 criteria that can be assessed as 'yes', 'no' or 'other' (cannot determine, not applicable or not reported). ${ }^{13}$

- Quality Assessment of Case-Control Studies from the NIH. A total of 12 items were assessed as 'yes', 'no' or 'other' (cannot determine, not applicable or nor reported). ${ }^{14}$

Any disagreement in the assessment of the risk of bias will be discussed to reach a consensus. A third researcher will be consulted to resolve the final decision if a consensus is not reached.

\section{Statistical analysis}

The characteristics of the included studies will be summarised in an ad hoc table. Then, we will extract the total incidence and will categorise it based on age (0-4, 5-9 and 10-14.9 years) and sex alone and in combination. In addition, we will analyse the data in different age groups, time periods (1994-2003, 2004-2012, 20132021), countries and regions whenever available.

For the meta-analysis, STATA V.15 software will be used to combine the pooled mean differences with $95 \%$ CIs. The Mantel-Haenszel fixed-effects model will be used if there is no evidence of heterogeneity ${ }^{15}$; otherwise, a random-effects model (Hartung-Knapp-Sidik-Jonkman) will be used. ${ }^{16}$ Study heterogeneity will be assessed using the $\mathrm{I}^{2}$ statistic. Here, $\mathrm{I}^{2}$ values of $<25 \%, 25 \%-50 \%$ and $>50 \%$ represent small, medium and large heterogeneity, 


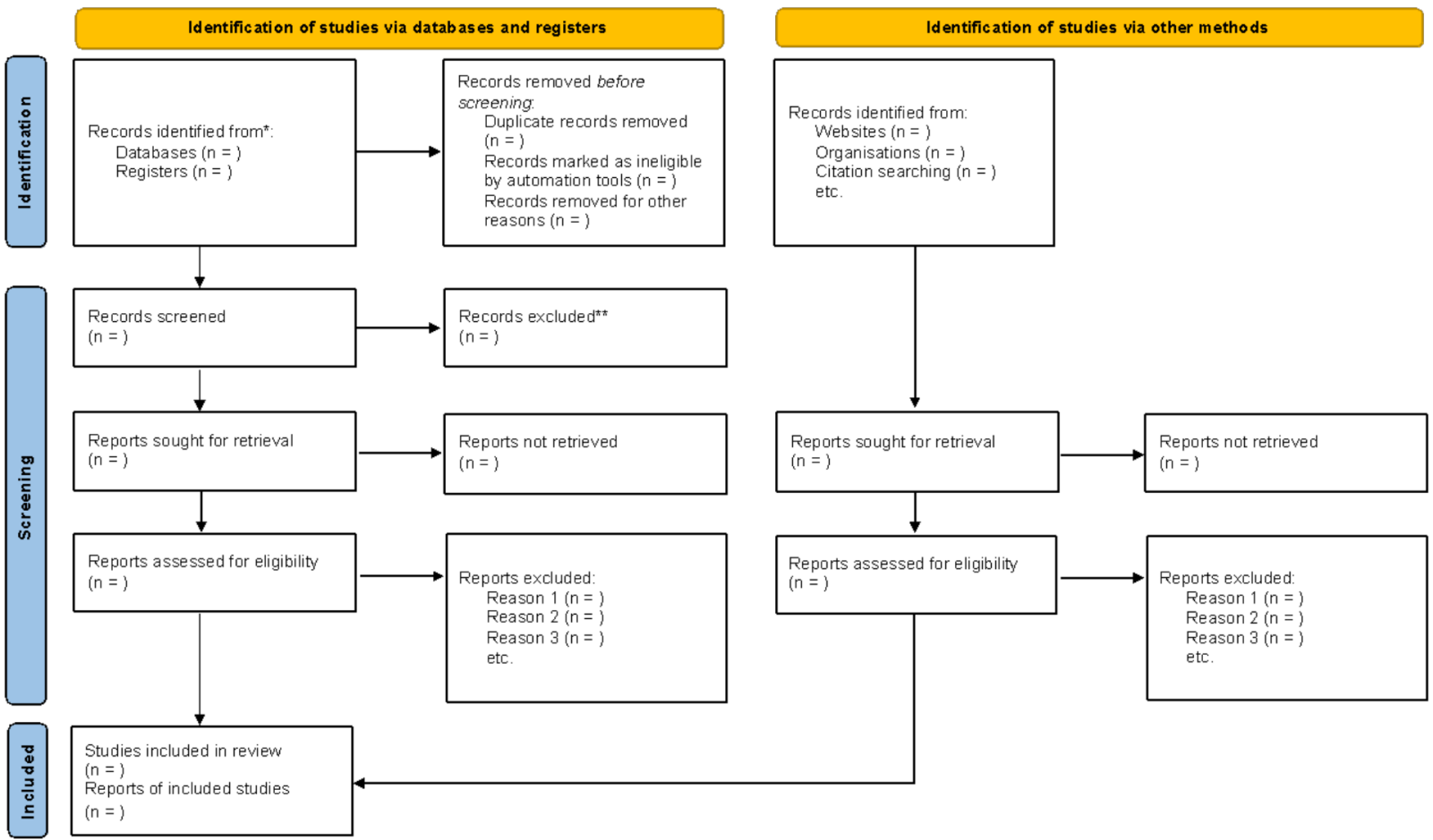

Figure 1 Preferred Reporting Items for Systematic Review and Meta-Analysis 2020 flow diagram for new systematic reviews, which included searches of databases, registers and other sources.

respectively. ${ }^{17}$ For this study, the Mantel-Haenszel fixedeffects method will be used when $\mathrm{I}^{2}$ is $<50 \%$, and HartungKnapp-Sidik-Jonkman random-effects when $\mathrm{I}^{2}$ is $\geq 50 \%$. The corresponding $\mathrm{p}$ values will also be considered. In addition, we will calculate the $\tau^{2}$ statistic to evaluate the size and clinical relevance of heterogeneity. Here, $\tau^{2}$ estimate values of 0.04 are interpreted as a low of clinical relevance of heterogeneity, 0.14 as moderate and 0.40 as substantial degree. ${ }^{11}$

First, the incidence estimates by countries will be pooled as an aggregate mean, weighted by the incidence of subjects with T1D; for each country the combined and stratified results by age groups, sex and time periods will be presented. Subsequently, the general point estimate will be calculated, and also subgroup analyses by European region will be performed, also stratified by age groups, sex and time periods.

\section{Subgroup and meta-regression analyses}

Subgroup and meta-regression analyses will be performed on the main factors causing heterogeneity, such as gender, age of study participants, period of time, countries, European regions (Atlantic, Iberian, Central and Mediterranean) and other study outcomes (HbA1c, obesity parameter), T1D family history, presence of autoantibodies, economic development and other geographic indicators, if available. Additionally, the design of the study and Quality in Prognosis Studies (QUIPS) Score will be considered in additional subgroup analyses. ${ }^{18}$

\section{Publication bias}

Finally, the publication bias for the main pooled data will be determined by visual inspection of the funnel plots, as well as using the method proposed by Egger. ${ }^{19}$

\section{DISCUSSION}

Monitoring T1D trends in children and adolescents across most European countries using objective diagnosis data and obtained in different European regions over time is important from a population health surveillance perspective. The EURODIAB study analyses the trends of 22 European countries based on annual records. However, many European countries are not included in these reports, which prevents the formation of a complete picture of Europe. In this sense, this systematic review and meta-analysis protocol aims to provide a precise, transparent and generalisable methodology for estimating the overtime trends of T1D for three age groups $(0-4,5-9$ and 10-14.9 years) across most European countries and regions from 1994 to June 2021.

A recent multicentre prospective study in several European countries showed a doubling in incidence rate within approximately 20 years in Europe. ${ }^{4}$ Despite a temporary slowing in the 2004-2008 period, an increased incidence rate in some high-risk areas, such as Finland, Norway or Sweden, has been confirmed. Thus, with the aim of identifying the evolution in the incidence of T1D, we propose to analyse three different subperiod groups (1994-2003, 2004-2012 and 2013-2021). 
T1D incidence rates in several European countries have been positively associated not only with strong genetic susceptibility, but also with country-level income ${ }^{20}$ and lifestyle or environmental risk factors. ${ }^{21-24}$ Previously, lower incidence rates could be related to an under-reporting of T1D cases, and the increase in T1D incidence may be attributed to improvements in the diagnosis and notification of true T1D cases. ${ }^{25}$ Monitoring T1D incidence based on periodic registries is highly significant to determine epidemiologic trends.

Based on all of the above, different sources of heterogeneity will be considered in this study. To verify whether participant characteristics, period of time, countries, European regions, QUIPS Score or other economic and geographic study outcomes could affect heterogeneity, several subgroups and random effects meta-regression will be conducted.

It is important to recognise the potential limitations of this research, such as inadequate reporting of methods and findings of the primary studies, publication bias, information bias or poor statistical analyses. We will consider the notion that these sources of bias will be greater in some regions and countries (eg, wealthy countries vs low-income countries). Therefore, it is important to summarise the information available in the manuscripts included.

In brief, due to the lack of complete information about T1D trends in children and adolescents in most European countries, it is important to conduct a systematic review and meta-analysis including children and adolescents over the last decades to provide high-quality evidence for monitoring and controlling this important public health problem. This protocol provides updated data for policy-makers and healthcare providers at national and continental levels to monitor this important public health concern that has shown an upward trend in recent years. Finally, the development of a new statistical model to assess studies addressing incidence trends of T1D is important because it could be useful to generate guidelines for future research on these types of issues.

Twitter Ana Díez-Fernández @Diez_ana

Contributors AD-F, MCR-G and MG-M designed the study. MG-M was the principal investigator and guarantor. VM-V and AD-F were the main coordinators of the study. MCR-G, AEM, AD-F and MG-M conducted the study. AEM, MG-M and VM-V gave statistical and epidemiological support. AD-F wrote the article with the support of MCR-G and MG-M. All authors reviewed and approved the final version of the manuscript.

Funding This study was funded by the Consejería de Educación, Cultura y Deportes-Junta de Comunidades de Castilla-La Mancha (grant number N/A) and European Regional Development Fund (grant number SBPLY/17/1 80 501/000533).

Disclaimer The funder did not have any role in the development of the manuscript. Competing interests None declared.

Patient and public involvement Patients and/or the public were not involved in the design, or conduct, or reporting, or dissemination plans of this research.

Patient consent for publication Not applicable.

Provenance and peer review Not commissioned; externally peer reviewed. 
Open access This is an open access article distributed in accordance with the Creative Commons Attribution Non Commercial (CC BY-NC 4.0) license, which permits others to distribute, remix, adapt, build upon this work non-commercially, and license their derivative works on different terms, provided the original work is properly cited, appropriate credit is given, any changes made indicated, and the use is non-commercial. See: http://creativecommons.org/licenses/by-nc/4.0/.

ORCID iD

Ana Díez-Fernández http://orcid.org/0000-0002-7673-986X

\section{REFERENCES}

1 DIAMOND Project Group. Incidence and trends of childhood type 1 diabetes worldwide 1990-1999. Diabet Med 2006;23:857-66.

2 International Diabetes Federation. IDF diabetes atlas. 9th edn. Brussels, Belgium, 2019. https://www.diabetesatlas.org

3 Patterson CC, Karuranga S, Salpea P, et al. Worldwide estimates of incidence, prevalence and mortality of type 1 diabetes in children and adolescents: results from the International diabetes Federation diabetes atlas, 9th edition. Diabetes Res Clin Pract 2019;157:107842-9.

4 Patterson CC, Harjutsalo V, Rosenbauer J, et al. Trends and cyclical variation in the incidence of childhood type 1 diabetes in 26 European centres in the 25 year period 1989-2013: a multicentre prospective registration study. Diabetologia 2019;62:408-17.

5 Piffaretti C, Mandereau-Bruno L, Guilmin-Crepon S, et al. Trends in childhood type 1 diabetes incidence in France, 2010-2015. Diabetes Res Clin Pract 2019;149:200-7.

6 Skordis N, Efstathiou E, Kyriakides TC, et al. Epidemiology of type 1 diabetes mellitus in Cyprus: rising incidence at the dawn of the 21st century. Hormones 2012;11:86-93.

7 Cardwell CR, Carson DJ, Patterson CC. Secular trends, disease maps and ecological analyses of the incidence of childhood onset type 1 diabetes in Northern Ireland, 1989-2003. Diabet Med 2007;24:289-95.

8 Forga Llenas L, Goñi Iriarte MJ, Cambra Contin K, et al. Incidence and temporal trends of childhood type 1 diabetes between 1975 and 2012 in Navarre (Spain). Gac Sanit 2015;29:51-4.

9 Moher D, Shamseer L, Clarke M, et al. Preferred reporting items for systematic review and meta-analysis protocols (PRISMA-P) 2015 statement. Syst Rev 2015;4:1.
10 Page MJ, McKenzie JE, Bossuyt PM. The PRISMA 2020 statement: an updated guideline for reporting systematic reviews. BMJ 2021;372.

11 Higgins JPT, Thomas J, Chandler J, eds. Cochrane Handbook for Systematic Reviews of Interventions version 6.2 (updated February 2021) [Internet]. Cochrane, 2021. www.training.cochrane.org/ handbook

12 Puhan MA, Schünemann HJ, Murad MH, et al. A GRADE Working group approach for rating the quality of treatment effect estimates from network meta-analysis. BMJ 2014;349:g5630.

13 NHLBI. Quality assessment tool for observational cohort and crosssectional studies. Bethesda, MD: National Institutes of Health, Department of Health and Human Services, 2014: 1-4.

14 NHLBI. Quality Assessment Tool of Case-Control Studies [Internet]. Bethesda, MD: National Institutes of Health, Department of Health and Human Services, 2014. https://www.nhlbi.nih.gov/health-topics/ study-quality-assessment-tools

15 MANTEL N, HAENSZEL W. Statistical aspects of the analysis of data from retrospective studies of disease. J Natl Cancer Inst 1959;22:719-48.

16 IntHout J, loannidis JPA, Borm GF. The Hartung-Knapp-SidikJonkman method for random effects meta-analysis is straightforward and considerably outperforms the standard DerSimonian-Laird method. BMC Med Res Methodol 2014;14:25.

17 Higgins JPT, Thompson SG, Deeks JJ, et al. Measuring inconsistency in meta-analyses. BMJ 2003;327:557-60.

18 Hayden JA, van der Windt DA, Cartwright JL, et al. Assessing bias in studies of prognostic factors. Ann Intern Med 2013;158:280-6.

19 Sterne JA, Egger M, Smith GD. Systematic reviews in health care: investigating and dealing with publication and other biases in metaanalysis. BMJ 2001;323:101-5.

20 Tamayo T, Rosenbauer J, Wild SH, et al. Diabetes in Europe: an update. Diabetes Res Clin Pract 2014;103:206-17.

21 Rasoul MA, Al-Mahdi M, Al-Kandari H, et al. Low serum vitamin-D status is associated with high prevalence and early onset of type-1 diabetes mellitus in Kuwaiti children. BMC Pediatr 2016;16:95.

$22 \mathrm{Knip} \mathrm{M}$, Siljander $\mathrm{H}$. The role of the intestinal microbiota in type 1 diabetes mellitus. Nat Rev Endocrinol 2016;12:154-67.

23 Kolb H, Elliott RB. Increasing incidence of IDDM a consequence of improved hygiene? Diabetologia 1994;37:729.

24 Howard SG. Developmental exposure to endocrine disrupting chemicals and type 1 diabetes mellitus. Front Endocrinol 2018;9:513.

25 Xia Y, Xie Z, Huang G, et al. Incidence and trend of type 1 diabetes and the underlying environmental determinants. Diabetes Metab Res Rev 2019;35:e3075. 